\title{
BMJ Open Prevalence and correlates of advance care directives among older Australians accessing health and residential aged care services: multicentre audit study
} Karen M Detering, ${ }^{1,2}$ Kimberly Buck, ${ }^{1}$ Rasa Ruseckaite, ${ }^{3}$ Helana Kelly, ${ }^{1}$
Marcus Sellars, ${ }^{1}$ Craig Sinclair, ${ }^{4}$ Josephine M Clayton, ${ }^{5}$ Linda Nolte ${ }^{1}$

To cite: Detering KM, Buck K, Ruseckaite R, et al. Prevalence and correlates of advance care directives among older Australians accessing health and residential aged care services: multicentre audit study. BMJ Open 2019;9:e025255. doi:10.1136/ bmjopen-2018-025255

- Prepublication history and additional material for this paper are available online. To view these files, please visit the journal online (http://dx.doi. org/10.1136/bmjopen-2018025255).

$\mathrm{KMD}$ and $\mathrm{KB}$ contributed equally.

Received 6 July 2018

Revised 20 November 2018

Accepted 5 December 2018

Check for updates

(c) Author(s) (or their employer(s)) 2019. Re-use permitted under CC BY-NC. No commercial re-use. See rights and permissions. Published by BMJ.

For numbered affiliations see end of article.

Correspondence to Dr Karen M Detering; karen.detering@austin.org.au

\section{ABSTRACT}

Objectives It is important that the outcomes of advance care planning (ACP) conversations are documented and available at the point of care. Advance care directives (ACDs) are a subset of ACP documentation and refer to structured documents that are completed and signed by competent adults. Other ACP documentation includes informal documentation by the person or on behalf of the person by someone else (eg, clinician, family). The primary objectives were to describe the prevalence and correlates of ACDs among Australians aged 65 and over accessing health and residential aged care services. The secondary aim was to describe the prevalence of other ACP documentation.

Design and setting A prospective multicentre health record audit in general practices $(n=13)$, hospitals $(n=12)$ and residential aged care facilities (RACFs; $n=26$ ).

Participants 503 people attending general practice, 574 people admitted to hospitals and 1208 people in RACFs.

Primary and secondary outcome measures Prevalence of one or more ACDs; prevalence of other ACP documentation.

Results $29.8 \%$ of people had at least one ACD on file. The majority were non-statutory documents (20.9\%). ACD prevalence was significantly higher in RACFs $(47.7 \%)$ than hospitals $(15.7 \%)$ and general practices $(3.2 \%)(p<0.001)$, and varied across jurisdictions. Multivariate logistic regression showed that the odds of having an ACD were positively associated with greater functional impairment and being in an RACF or hospital compared with general practice. $21.6 \%$ of people had other ACP documentation. Conclusions In this study, $30 \%$ of people had ACDs accessible and a further $20 \%$ had other ACP documentation, suggesting that approximately half of participants had some form of ACP. Correlates of ACD completion were greater impairment and being in an RACF or hospital. Greater efforts to promote and standardise ACDs across jurisdictions may help to assist older people to navigate and complete ACDs and to receive care consistent with their preferences. Trial registration number ACTRN12617000743369.

\section{INTRODUCTION}

Advance care planning (ACP) is a process of planning for future healthcare, whereby the

\section{Strengths and limitations of this study}

- This Australian national, multicentre, cross-sectional health record audit aimed to determine the prevalence of advance care directives among people aged 65 years and older accessing Australian hospitals, residential aged care facilities and general practices.

- Data collectors were trained in the audit methodology using a standardised approach.

- The results of this study will inform future steps towards improved advance care planning data collection methodology, implementation strategies and evaluation processes, within Australia and internationally, with the aim of improving advance care planning uptake.

- The recruitment strategy, using an expression of interest process, is likely to have resulted in a selection bias towards organisations with an interest in advance care planning.

- Not all Australian states and territories were similarly represented, limiting the generalisability of findings across Australia.

person's values and preferences are made known. ACP may also involve the appointment of a substitute decision-maker. ${ }^{1}$ The ultimate goal of ACP is to align the actual care the person receives with their preferences. ${ }^{2}$ While ACP conversations are valuable in their own right, completion of advance care directives (ACDs) is useful because they provide evidence and support for substitute decision-makers and clinicians who need to consider and advocate for the person's expressed preferences if the person subsequently loses decision-making capacity. ${ }^{3-5}$

Internationally, there is considerable variation in the terminology, documentation and legislative frameworks related to ACDs. ${ }^{6-11}$ In Australia, an ACD is a type of document recognised by common law or statutory legislation that is completed and signed by a competent adult. It can record 
the person's preferences for future care and appoint a substitute decision-maker to make decisions about future care. ${ }^{12}$

Although all Australian jurisdictions recognise ACDs under legislation (statutory) or common law (non-statutory), terminology differs across jurisdictions. While early statutory ACDs mostly focused on specific treatment instructions and/or appointment of a substitute decision-maker, increasingly, statutory ACDs also include values and goals elements. ${ }^{13}$ Non-statutory ACDs generally focus more broadly on a person's values and goals for future care, but may also include specific instructions regarding treatment. ${ }^{14}$ Currently in Australia, all jurisdictions provide a statutory ACD for appointing a substitute decision-maker, and all except New South Wales and Tasmania offer statutory ACDs for recording preferences for care. ${ }^{6}$ Non-statutory ACDs are also used in Australia, ${ }^{13}$ but the legal standing of these documents has only been tested in New South Wales. ${ }^{6} 14$

ACP may also result in 'other ACP documentation'. ${ }^{15}$ These are documents that relate to ACP but do not meet the definition of an ACD,${ }^{12}$ and may include documents written on behalf of a person without capacity (by family, substitute decision-makers or clinicians) or informal, personally written letters. ${ }^{15}$ Additionally, there are documents written by health professionals that describe medical action to be taken in the event of an emergency. In Australia, these include goals of care forms and resuscitation orders and serve a similar purpose to that of the Physician Orders for Life-Sustaining Treatment. ${ }^{16}$

ACP is recognised as good medical practice, ${ }^{17-20}$ and is supported within policy and legislative frameworks internationally. ${ }^{10} 11$ ACP is widely recognised in Australian policy and legislative frameworks ${ }^{312} 142122$ including the National Palliative Care Strategy $2010^{21}$ and the 2017 Productivity Commission report, 'Introducing Competition and Informed User Choice into Human Services'. ${ }^{23}$ However, little is known about the current prevalence of ACDs in Australia. The National Framework for Advance Care Directives $2011^{14}$ and the evaluation of the National Palliative Care Strategy in $2016^{24}$ identified the need for baseline data on ACDs. Previous attempts to estimate prevalence within Australia and internationally are scarce and have mostly relied on self-report, been limited to only one type of ACD or restricted to one region or healthcare setting. ${ }^{25-40}$ Without detailed national ACD prevalence data, it is difficult for governments and services to monitor the effectiveness of ACP policy and implementation initiatives. ${ }^{12} 1421$

The primary aims of this study were to describe the prevalence of ACDs among older Australians accessing selected health and aged care services, to document the types of ACDs completed, to explore the characteristics of those with an ACD and to use learnings to inform the future study of ACD prevalence in Australia. The secondary aim was to determine the prevalence of other ACP documentation.

\section{METHODS}

Data reported in this article originate from a large-scale national study examining the prevalence of ACDs in selected Australian general practices, hospitals and residential aged care facilities. The study involved a prospective multicentre audit of health records and a self-report survey of a subset of people whose records were included in the audit. The study protocol has been reported elsewhere. ${ }^{15}$ This article focuses on the audit component of the study. Data relevant to the survey and to clinical care plans will be reported elsewhere. A brief summary of the audit methodology is outlined here.

Informed consent was obtained for the survey component of the study. The Strengthening the Reporting of Observational Studies in Epidemiology guidelines were followed in the reporting of this cross-sectional study. ${ }^{41}$

\section{Setting, sample, recruitment and data collection}

Participating sites were Australian general practices, hospitals and residential aged care facilities. Health records were audited for people aged 65 years and older (50 years and older for Aboriginal and Torres Strait Islander peoples) who had been admitted to hospital or living in a residential aged care facility for more than 48 hours, and those visiting general practice on the study day(s). Sites from all eight Australian jurisdictions were invited to participate via expression of interest. Additional sites were approached aiming to promote representativeness across sectors and jurisdictions. Participating sites received \$A100 per audited health record, to a maximum of $\$ A 5000$ per site.

Health records of people in the hospital and residential aged care facilities settings were randomly selected from a list of eligible people, while in general practices consecutive eligible records were audited. ${ }^{15}$

Data collectors from each site were trained in the audit methodology using a pilot-tested and standardised approach. Data collectors were instructed to search paper and/or electronic health records for a maximum of 15 min for ACDs and other ACP documentation. Because ACP legislation is determined separately by each Australian state or territory, data collection occurred using a jurisdiction-specific instrument. Data were entered and stored on a secure cloud-based database specifically built for this project.

\section{Health record audit}

\section{Demographic and clinical information}

Data extracted included age, gender, country of birth, indigenous status, English language status, diagnostic category and Eastern Cooperative Oncology Group (ECOG) status ( $0=$ fully active to $4=$ completely disabled) ${ }^{42}$

\section{Presence of ACDs and other ACP documentation}

For the purposes of this study, ACDs were defined as formal documents recognised by statutory legislation (statutory ACD) or common law (non-statutory ACD) completed and signed by a competent adult (online 
supplementary appendix 1). Any ACP documentation that did not meet the definition of an ACD was classified as 'other ACP documentation'. Data extracted during the audit included the type and name of ACDs or other ACP documentation identified in the health record. Data collectors were trained to categorise located documents as statutory ACD: preferences for care, statutory ACD: substitute decision-maker, non-statutory ACDs or other ACP documentation. By collecting the name of any documentation identified in the health record, it was also possible to ensure documents were categorised correctly, and to explore the characteristics of documents being used. Analysis of text descriptions of the names of documents identified indicated that 38 documents were misclassified by data collectors during data collection. These 38 documents were recoded prior to analysis. Specifically, 14 documents that were incorrectly classified as statutory ACD: preferences for care were reclassified as either statutory ACD: substitute decision-maker $(n=6)$, non-statutory ACDs $(n=3)$ or other ACP documentation $(n=5)$. In addition, 24 documents that were incorrectly classified as other ACP documentation were reclassified as statutory ACD: preferences for care $(n=13)$ or non-statutory ACDs $(n=11)$.

\section{Outcome measures}

The primary outcome was the prevalence of at least one ACD (statutory ACD: preferences for care, statutory ACD: substitute decision-maker and/or non-statutory ACD) in the health record. The secondary outcome was a prevalence of other ACP documentation.

\section{Statistical analysis}

Statistical analyses were conducted using SPSS V.24.0 (IBM). ACD prevalence overall, and for the three types of ACDs (statutory ACD: preferences for care, statutory ACD: substitute decision-maker and non-statutory ACD), was calculated for the total sample and separately for settings and jurisdictions. The secondary outcome of the prevalence of other ACP documentation was calculated for the full sample.

Correlates of having an ACD on file were first explored through univariate analyses. Factors tested were: age, gender, jurisdiction, setting, country of birth, indigenous status, English language status, a range of medical conditions, morbidity and ECOG status. Variables with univariate associations of $\mathrm{p}<0.15$ were entered simultaneously into a multivariate logistic regression model to identify factors that characterised people with ACDs from those without. For this step, the level of statistical significance was lowered to 0.05 . The multivariate analysis is presented here. ORs for having at least one ACD on file are reported, together with $95 \%$ CIs. In a supplementary logistic regression analysis, data were weighted for age, gender and jurisdiction to compensate for under-representation from the younger (65-75 years) cohort and over-representation from females and people living in Victoria. Weighting was conducted using the latest

\begin{tabular}{lc}
\hline \multicolumn{1}{l}{ Table $1 \quad$ Characteristics of study sites $(\mathrm{n}=51)$} \\
\hline Characteristic & $\mathbf{n}(\%)$ \\
\hline Jurisdiction & $1(2.0)$ \\
Australian Capital Territory & $14(27.5)$ \\
New South Wales & $7(13.6)$ \\
Queensland & $5(9.8)$ \\
South Australia & $1(2.0)$ \\
Tasmania & $23(45.1)$ \\
Victoria & \\
Sector & $12(23.5)$ \\
Hospital & $26(51.0)$ \\
Residential aged care facility & $13(25.5)$ \\
General practice & \\
Location & $28(54.9)$ \\
$\quad$ Metropolitan & $23(43.1)$ \\
$\quad$ Rural or regional & \\
Service funding & $12(23.5)$ \\
Government & $22(43.1)$ \\
Not for profit & $17(33.4)$ \\
Private &
\end{tabular}

Australian Bureau of Statistics data. ${ }^{43}$ To account for variables with low cell counts in the weighted analysis, 10 people who were of indigenous background and aged less than 65 years were excluded from the analysis and the three smallest jurisdictions (Australian Capital Territory, South Australia and Tasmania) were combined.

\section{Patient and public involvement}

People whose health records were included in the audit were not involved in the design nor in the recruitment or any other aspect of conducting the study. Results of the study cannot be directly shared with participants as only de-identified data were collected, however, academic outputs will be publicised through community networks, social media and traditional media channels. All sites and jurisdictions involved in the study have been provided with de-identified individualised reports of study findings, including how their site/jurisdiction compares to others. The specific intent of providing these reports is to inform service-level initiatives and future ACP programmes and policy.

\section{RESULTS}

Data were collected from 51 sites between September 2017 and January 2018. All jurisdictions except the Northern Territory and Western Australia were represented (table 1 ).

From a total of 2298 audited records, 13 records were excluded because ages were outside specified criteria, leaving 2285 participants. Sample characteristics are presented in table 2. 
Table 2 Sample characteristics ${ }^{*}(n=2285)$

\section{Characteristic}

\begin{tabular}{ll}
\hline Age & \\
Years & Median=83.0; \\
& IQR=15
\end{tabular}

$\begin{array}{lr}\text { Sex } & \\ \text { Male } & 885(38.7) \\ \text { Female } & 1400(61.3)\end{array}$

Healthcare setting

$\begin{array}{lr}\text { General practice } & 503(22.0) \\ \text { Hospital } & 574(25.1) \\ \text { Residential aged care facility } & 1208(52.9)\end{array}$

Jurisdiction

\begin{tabular}{|c|c|}
\hline Australian Capital Territory & $31(1.4)$ \\
\hline New South Wales & $655(28.6)$ \\
\hline Queensland & $351(15.4)$ \\
\hline South Australia & $239(10.4)$ \\
\hline Tasmania & $50(2.2)$ \\
\hline Victoria & $959(42.0)$ \\
\hline \multicolumn{2}{|l|}{ Country of birth } \\
\hline Australia & $1343(58.7)$ \\
\hline Other & $536(23.5)$ \\
\hline Missing & $406(17.8)$ \\
\hline \multicolumn{2}{|l|}{ Indigenous status } \\
\hline Aboriginal and Torres Strait Islander & $27(1.2)$ \\
\hline $\begin{array}{l}\text { Non-Aboriginal and Torres Strait } \\
\text { Islander }\end{array}$ & 2090 (91.4) \\
\hline Missing & $168(7.4)$ \\
\hline \multicolumn{2}{|l|}{ Speaks English } \\
\hline Yes & $1804(78.8)$ \\
\hline Interpreter required & $73(1.3)$ \\
\hline Missing & $408(17.9)$ \\
\hline \multicolumn{2}{|l|}{ Medical condition† } \\
\hline Circulatory system (yes) & $1452(63.5)$ \\
\hline $\begin{array}{l}\text { Musculoskeletal and connective tissue } \\
\text { (yes) }\end{array}$ & $1293(56.5)$ \\
\hline Dementia (yes) & $719(31.5)$ \\
\hline Urinary/excretory, reproductive (yes) & $719(31.5)$ \\
\hline $\begin{array}{l}\text { Endocrine, nutritional, metabolic } \\
\text { disorders (yes) }\end{array}$ & $673(29.5)$ \\
\hline Neurological system (yes) & $638(27.9)$ \\
\hline Gastrointestinal system (yes) & $627(27.4)$ \\
\hline Respiratory system (yes) & $626(27.4)$ \\
\hline Mental IIIness (yes) & $534(23.4)$ \\
\hline Cancer (yes) & $458(20.0)$ \\
\hline Other (yes) & 369 (16.1) \\
\hline \multicolumn{2}{|l|}{ Morbidity } \\
\hline Unimorbid & 263 (11.5) \\
\hline
\end{tabular}

Continued

\begin{tabular}{lr} 
Table 2 Continued & \\
\hline Characteristic & \\
\hline Comorbid & $441(19.3)$ \\
Multimorbid & $1581(69.2)$ \\
ECOG status $\neq$ & \\
0 & $82(3.6)$ \\
1 & $144(6.3)$ \\
2 & $327(14.3)$ \\
3 & $761(33.3)$ \\
4 & $292(12.8)$ \\
Missing & $679(29.7)$ \\
\hline
\end{tabular}

Cannot carry on any self-care; confined to bed or chair more than $50 \%$ of waking hours; confined to bed or chair. ${ }^{21}$

${ }^{*}$ Reported as median and IQR for continuous variables and as frequency (percentage) for categorical variables.

†Participant may have more than one medical condition.

ҒECOG performance status grades: $0=$ fully active, able to carry on all predisease performance without restriction; up and about more than $50 \%$ of waking hours; $1=$ restricted in physically strenuous activity, but ambulatory and able to carry out work of a light or sedentary nature; $2=$ ambulatory and capable of all self-care but unable to carry out work activities; $3=$ capable of only limited selfcare; 4=completely disabled.

ECOG, Eastern Cooperative Oncology Group.

\section{Prevalence of ACDs}

Prevalence rates are summarised in table 3. The overall prevalence of having at least one ACD was $29.8 \%$. Non-statutory ACDs were the most common ACDs identified $(20.9 \%)$, followed by statutory ACD: substitute decision-maker $(10.9 \%)$ and statutory ACD: preferences for care $(2.7 \%)$. There were 24 differently named non-statutory ACDs (online supplementary appendix 2). Almost all $(94.6 \%)$ ACDs were identified within 5 min and most (80\%) were found within paper-based records.

People in residential aged care facilities were significantly more likely to have an ACD (47.7\%) than people in hospitals $(15.7 \%)$ or general practice $(3.2 \%)$, $\chi^{2}(2)=409.36, \varphi=0.42 \quad(95 \%$ CI 0.39 to 0.46$), \mathrm{p}<0.001$. Overall, prevalence rates were highest in South Australia $(53.1 \%)$.

\section{Correlates of ACDs}

Based on univariate analyses, age, gender, jurisdiction, setting, musculoskeletal conditions, dementia, mental illness, urinary/excretory and reproductive conditions, cancer, morbidity, and ECOG status were associated with the presence of an ACD and were included in multivariate analyses. The variable 'jurisdiction' was subsequently excluded because a low count in one cell $(n=31)$ introduced instability to the model. To account for missing data on the ECOG variable $(n=674)$, we attempted multiple imputation. However, this approach was ineffective because although it boosted sample size, it also greatly increased the variance and reduced the efficiency of the model. Thus, for the purposes of the regression model, the 674 participants with missing data on the 


\begin{tabular}{|c|c|c|c|c|}
\hline & & Type of ACD* & & \\
\hline & $\begin{array}{l}\text { At least one ACD } \\
\text { overall } \\
\text { n (\%) }\end{array}$ & $\begin{array}{l}\text { Statutory ACD: } \\
\text { preferences for } \\
\text { care } \\
\mathrm{n}(\%) \\
\end{array}$ & $\begin{array}{l}\text { Statutory ACD: } \\
\text { substitute decision- } \\
\text { maker } \\
\mathrm{n}(\%)\end{array}$ & $\begin{array}{l}\text { Non-statutory } \\
\text { ACD } \\
\text { n (\%) }\end{array}$ \\
\hline Total sample $(n=2285)$ & $682(29.8)$ & $62(2.7)$ & $250(10.9)$ & 477 (20.9) \\
\hline Healthcare sector & & & & \\
\hline General practice $(n=503)$ & $16(3.2)$ & $1(0.2)$ & $11(2.2)$ & $5(1.0)$ \\
\hline Hospital $(n=574)$ & $90(15.7)$ & $15(2.6)$ & $68(11.8)$ & $33(5.7)$ \\
\hline RACF $(n=1208)$ & $576(47.7)$ & $46(3.8)$ & $171(14.2)$ & $439(36.3)$ \\
\hline Jurisdiction & & & & \\
\hline Australian Capital Territory $(n=31)$ & $0(0.0)$ & $0(0.0)$ & $0(0.0)$ & $0(0.0)$ \\
\hline General practice & - & - & - & - \\
\hline Hospital & - & - & - & - \\
\hline RACF & $0(0.0)$ & $0(0.0)$ & $0(0.0)$ & $0(0.0)$ \\
\hline New South Wales $(n=655)$ & $241(36.8)$ & N/A & $19(2.9)$ & 235 (35.9) \\
\hline General practice & $5(4.3)$ & N/A & $4(3.5)$ & $1(0.9)$ \\
\hline Hospital & - & N/A & - & - \\
\hline RACF & $236(43.7)$ & N/A & $15(2.8)$ & $234(43.3)$ \\
\hline Queensland $(n=351)$ & $141(40.2)$ & $24(6.8)$ & $81(23.1)$ & $67(19.1)$ \\
\hline General practice & $1(2.9)$ & $0(0.0)$ & $0(0.0)$ & $1(2.9)$ \\
\hline Hospital & $36(21.7)$ & $10(6.0)$ & $29(17.5)$ & $2(1.2)$ \\
\hline RACF & $104(69.3)$ & $14(9.3)$ & $52(34.7)$ & $64(42.7)$ \\
\hline South Australia $(n=239)$ & $127(53.1)$ & $33(13.8)$ & $97(40.6)$ & 39 (16.3) \\
\hline General practice & - & - & - & - \\
\hline Hospital & $5(8.9)$ & $2(3.6)$ & $3(5.4)$ & $1(1.8)$ \\
\hline RACF & $122(66.7)$ & $31(16.9)$ & $94(51.4)$ & $38(20.8)$ \\
\hline Tasmania $(n=50)$ & $7(14.0)$ & N/A & $6(12.0)$ & $1(2.0)$ \\
\hline General practice & - & N/A & - & - \\
\hline Hospital & - & N/A & - & - \\
\hline RACF & $7(14.0)$ & N/A & $6(12.0)$ & $1(2.0)$ \\
\hline Victoria $(n=959)$ & $166(17.3)$ & $5(0.5)$ & $47(4.9)$ & $135(14.1)$ \\
\hline General practice & $10(2.8)$ & $1(0.3)$ & $7(2.0)$ & $3(0.8)$ \\
\hline Hospital & 49 (13.9) & $3(0.9)$ & $36(10.2)$ & $30(8.5)$ \\
\hline RACF & $107(42.1)$ & $1(0.4)$ & $4(1.6)$ & $102(40.2)$ \\
\hline
\end{tabular}

A dash $(-)$ indicates a particular sector/jurisdiction that was not represented in the study. N/A indicates a document that is not available in a particular jurisdiction.

${ }^{*}$ Participants may have more than one type of ACD.

ACD, advance care directive; RACF, residential aged care facility.

ECOG variable (29.6\% of the total sample) were removed using listwise deletion.

Results of the multivariate logistic regression analysis are presented in figure 1 . There were higher odds of having an ACD for those who were in a residential aged care facility or hospital compared with general practice (OR 27.04; 95\% CI 6.44 to 113.60 and OR $7.94 ; 95 \%$ CI 1.89 to 33.44, respectively), and for those rated as ECOG grades 2,3 or 4 (moderate to very severe disability) compared with those rated as ECOG grade 0 (fully active;
OR 4.26; 95\% CI 1.61 to 11.29 , OR 2.91; $95 \%$ CI 1.11 to 7.60 and OR 3.53 ; $95 \%$ CI 1.32 to 9.40 , respectively).

After the data were weighted for age, gender and jurisdiction, the overall prevalence of ACDs was reduced to $21.4 \%$. Using the weighted data, the results of the multivariate logistic regression model showed that healthcare setting no longer significantly predicted the presence of an ACD in the health record. However, several other variables became significant in the weighted model: there were higher odds of having an ACD for those who were 


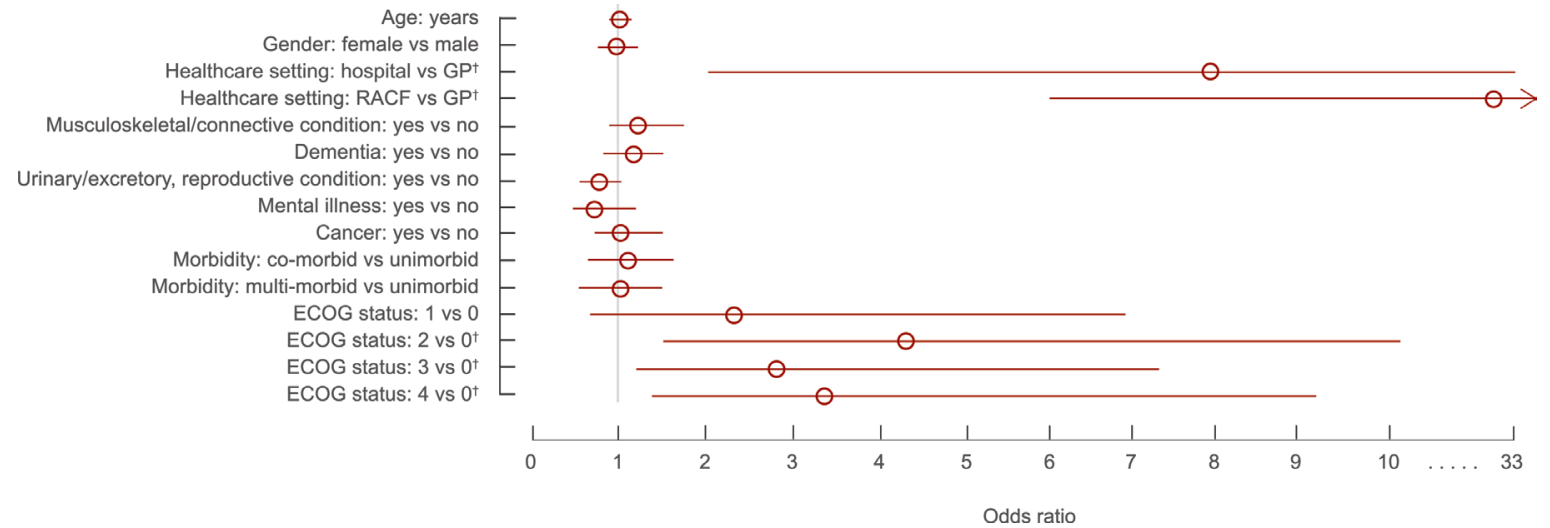

Figure 1 ORs for factors associated with having at least one advance care directive $(n=1606) . R^{2}=0.17$ (Nagelkerke). Model $\chi^{2}(15)=206.47, p<0.0001$. Bars represent $95 \%$ Cls. Factors for which the $95 \% \mathrm{Cl}$ does not include the value of 1 (indicated by the grey line) are statistically significant. An OR of 1 indicates no association between a predictor variable and the odds of having an $A C D$. $\nmid P<0.05$ compared with reference category. ECOG, Eastern Cooperative Oncology Group; GP, general practice; RACF, residential aged care facility.

older (OR 1.03; $95 \%$ CI 1.01 to 1.05$)$, those with a urinary or reproductive condition (OR 1.63; 95\% CI 1.17 to 2.25 ), those with cancer (OR 1.93; 95\% CI 1.29 to 2.87) and those rated as ECOG grade 1 (low disability) compared with those rated as ECOG grade 0 (OR 6.15; 95\% CI 1.37 to 27.54). Consistent with the unweighted model, there were also higher odds of having an ACD for those who were rated as ECOG grades 2, 3 or 4 compared with those rated as ECOG grade 0 (OR 16.88; 95\% CI 4.19 to 67.94, OR 19.35; 95\% CI 4.80 to 77.97 and OR $20.60 ; 95 \%$ CI 5.01 to 84.67 , respectively). Full results of the weighted model are presented in online supplementary appendix 3.

\section{Prevalence of other ACP documentation}

The prevalence of other ACP documentation was 21.6\% $(n=493)$. Of the 493 people with other ACP documentation, 457 (93\%) only had other ACP documentation (ie, did not also have an ACD). Therefore, $20 \%$ of the total sample of 2285 records contained only other ACP documentation. Only $20 \%$ of other ACP documentation was written by the person themselves. There were 37 differently named types of other ACP documentation (online supplementary appendix 4).

\section{DISCUSSION}

This study found that approximately one-third of older Australians in selected general practices, hospitals and residential aged care facilities had at least one ACD in their health record. Most of these $(21 \%)$ were non-statutory documents, despite the availability of legislated documents in most Australian states and territories. Less than $3 \%$ of the sample completed a statutory ACD: preferences for care, and only $11 \%$ completed a statutory ACD: substitute decision-maker. The odds of having an ACD were higher in residential aged care facilities than hospitals and general practices, with considerable variation between jurisdictions. The odds of having an ACD were also higher for those with functional impairment. In addition, 20\% of people had ACP documentation other than ACDs in their files, showing that approximately $50 \%$ of participants had some form of ACP. However, there was an extensive range of documents used (24 different non-statutory ACDs and 37 different other ACP documentation).

This study found that, despite ACDs being governed by specific legislation across most Australian jurisdictions, non-statutory ACDs were much more likely to be identified. Traditionally, statutory ACDs have predominantly focused on limitations of treatment, whereas non-statutory documents have focused on the person's values, goals and reasoning behind decisions. Thus, non-statutory ACDs have been perceived as being more flexible and applicable to various future medical situations. ${ }^{6}{ }^{14}$ However, lack of clarity regarding the legal status of non-statutory ACDs may reduce clinician confidence and therefore the likelihood that preferences are actually followed in practice. ${ }^{64}$ Statutory ACDs also have procedural safeguards to protect against freedom from duress, fraud or undue influence. ${ }^{6}{ }^{13}$ However, witnessing and other procedural requirements also present barriers to completion. ${ }^{6}$ Recently, values-based elements have been included within statutory ACDs in some jurisdictions in Australia (online supplementary appendix 1, table 2). There is also increased access to education for people and practitioners to facilitate completion of statutory ACDs. ${ }^{13}$ These approaches aim to support improved flexibility and promote opportunities for valid completion of statutory ACDs while also providing legal clarity and protections for persons, substitute decision-makers and clinicians. Furthermore, there have been calls in Australia to standardise and simplify ACDs, and to harmonise legislation. ${ }^{6}{ }^{14}{ }^{23} \mathrm{~A}$ large number of different types of documents identified in this study (online supplementary appendices 2 and 4) support these efforts. 
People in residential aged care facilities were significantly more likely to have an ACD than people in hospitals or attending general practice. As providers of care to one-third of people approaching the end of life, residential aged care facilities play a vital role in facilitating ACP and enacting ACDs where they exist. ${ }^{23} 46$ The lower prevalence in hospitals and very low prevalence in general practices suggests that further efforts are needed to increase uptake of ACP in these settings, and to understand barriers to this occurring.

It is estimated that approximately $30 \%$ of people admitted to hospitals are likely to be in their last year of life, ${ }^{47}$ highlighting the important role hospitals have in supporting people to participate in ACP and to develop, review, update or enact ACDs. ${ }^{3}{ }^{48}$ However, research suggests that inadequate systems, support structures and ACP training for clinicians in hospitals can lead to a reluctance to have conversations and develop ACDs. ${ }^{234950}$ Addressing these barriers would be beneficial to increasing uptake in the hospital sector.

In addition, while general practitioners are well placed to hold ACP conversations given their often longstanding and trusted relationships with patients, ${ }^{48} 51$ ACP conversations require time and effort, and in most circumstances, cannot be completed on a single visit. The pressure of managing conflicting patient and clinician priorities within short appointments and the absence of suitable remuneration can discourage primary care providers from dedicating time to ACP. ${ }^{48}$ Increasing ACP in primary care could be supported through the inclusion of ACP into routine health assessments, encouraging a multidisciplinary approach and using funding for regular consultations to facilitate remuneration for the time required. ${ }^{234852}$ For the true potential of ACP to be achieved across all health sectors, a system-wide and multifaceted approach to ACP implementation is necessary. Key elements include increasing community awareness and uptake earlier in illness trajectories, provision of training and support for clinicians and aged care workers, and improving storage and accessibility of ACDs at the point of care. ${ }^{13} 1423244852$

Prior to weighting for age, gender and jurisdiction, the odds of having an ACD were higher for people with functional impairment. It is likely that people with greater dependency engage more regularly with healthcare services and that functional impairment acts as an ACP trigger. Progressive disability may also increase the relevance of ACP for individuals. ${ }^{53}$ However, people with other conditions, including dementia and cancer, were no more likely to have ACDs than people without these conditions. Future ACP implementation and policy should continue to promote ACP among people with all serious, progressive and chronic conditions. ${ }^{348}$

After weighting for age, gender and jurisdiction, the overall prevalence of ACDs was reduced from $30 \%$ to $21 \%$. The weighted model also showed greater odds of having an ACD for people who were older, people with a urinary or reproductive condition and people with cancer. The study sample was under-represented in the younger cohort (65-75 years) and over-represented in females and the jurisdiction of Victoria in comparison to the general Australian population, making it difficult to draw firm conclusions about the weighted analysis. ${ }^{43}$ Nonetheless, given the weighted regression model increased the effect of the younger cohort of the sample (those aged 65-75 years) on the results, it is likely that these younger age groups were more likely to have an ACD if they had a urinary/reproductive condition or cancer. Further research among this age cohort would help to clarify these findings.

Consistent with previous work, ${ }^{40} \mathrm{ACD}$ prevalence rates varied between jurisdictions. However, results should be interpreted with caution given not all jurisdictions were similarly represented. Future prevalence studies should aim to recruit more representative samples. Nevertheless, variation in legislative frameworks and policy across Australia is likely to contribute to observed differences. ${ }^{40}$

The overall ACD prevalence found here was higher than previous Australian estimates, which range from $0.2 \%$ in residential aged care facilities,${ }^{37}$ to $13 \%$ among older persons in emergency departments, ${ }^{39}$ to $14 \%$ among community participants, ${ }^{40}$ to $11 \%-22 \%$ for recognised legal ACDs among adults in South Australia. ${ }^{25}$ Past studies have typically focused on prevalence estimates for one type of ACD. The higher prevalence reported here may reflect the inclusion of statutory and non-statutory ACD and may also relate to the age of the population studied. A recent South Australian study found that ACDs were most common among those aged 65 years and over.

From an international perspective, the results found in this study are comparable to a recent systematic review of 150 studies in the USA, which reported an average ACD prevalence of $36.7 \% .^{34}$ However, other international ACD prevalence estimates vary. In aged care settings, prevalence rates range from $11 \%-36 \%$ in Germany, ${ }^{2627}$ to $16 \%$ in Taiwan, ${ }^{28}$ to $59 \%$ in the USA. ${ }^{29}$ In general practice, a prevalence of $33 \%$ was found in one European study ${ }^{30}$ while a Canadian study reported an ACD prevalence of $20 \%{ }^{31}$ In the hospital sector, ACD prevalence rates of $12 \%-26 \%$ have been reported in studies in the USA. ${ }^{32} 33$ Apart from any actual differences between jurisdictions internationally, these varying prevalence estimates are likely to reflect a wide range of methodologies and study populations and variation in the quality of studies.

In this study, a prospective multisite audit methodology was used in an attempt to overcome the potential bias inherent in other methodologies, such as self-report and retrospective design. This study also used a standardised approach to audit methodology and ACD classification, with the aim of facilitating meaningful comparison between sites. However, recruitment was via expression of interest and this may have resulted in selection bias towards sites with an interest in ACP. This, together with the lack of representation across jurisdictions and health sectors, limits the extent to which the findings are generalisable across Australia. Given the audit methodology 
used, it is not possible to determine quality and extent of ACP conversations known to be an important determinant of a successful ACP programme. ${ }^{45}$ An additional limitation of the audit methodology is that it is unknown whether the presence of any ACDs or a specific type of ACDs translates into care that is consistent with the person's preferences, the ultimate goal of ACP. ${ }^{1}$ Nonetheless, using a standardised audit methodology allows for scalable national measurement of documentation of completed ACDs, which is one key component of ACP. Finally, missing data on the ECOG status variable (affecting approximately 20\% of the sample) may limit the findings related to predictors of ACD completion.

The findings of this study provide a number of avenues for further implementation activities and research, not only within the Australian context, but also internationally. This could include understanding how individuals conceptualise and make decisions regarding ACP, how clinicians use ACDs, whether there are particular types of ACDs that are more useful, and the utility of other ACP documentation in improving care consistent with a person's preferences. Furthermore, improved understanding regarding the facilitators and barriers to ACP uptake in general practice, hospitals and residential aged care facilities, and the potential consequences of not having an ACD available to guide medical decision-making at the point of care is necessary if the maximal value of ACP and ACDs is to be achieved.

\section{CONCLUSION}

This study provides one of the most detailed and comprehensive estimates to date on ACD prevalence in Australian general practices, hospitals and residential aged care facilities, as well as one of the largest multisite data sets regarding ACD prevalence among older people internationally. Overall, approximately $30 \%$ of older Australians had at least one ACD documented in their health record, and the majority of these were non-statutory documents. The correlates of ACD completion were greater functional impairment and being in an aged care facility or hospital compared with attending general practice. Further work is required to increase the uptake of ACP and documentation of preferences in ACDs. This might include greater promotion of ACP, particularly among high-risk populations, public and health professional education campaigns supporting the use of statutory ACDs, and efforts to standardise documentation within and between Australian jurisdictions. Using standardised measurement of ACD prevalence will facilitate evaluation of implementation efforts and support meaningful comparisons within Australia and internationally.

\section{Author affiliations}

${ }^{1}$ Advance Care Planning Australia, Austin Health, Heidelberg, Victoria, Australia

${ }^{2}$ Faculty of Medicine, Dentistry and Health Science, University of Melbourne, Melbourne, Victoria, Australia

${ }^{3}$ Department of Epidemiology and Preventative Medicine, Monash University, Melbourne, Victoria, Australia
${ }^{4}$ Rural Clinical School of Western Australia, University of Western Australia, Albany, Western Australia, Australia

${ }^{5}$ Centre for Learning and Research in Palliative Care, Hammond Care, Greenwich Hospital and Sydney Medical School, University of Sydney, Sydney, New South Wales, Australia

Acknowledgements We acknowledge the support and contribution of the National Prevalence Study Advisory Group, Sue Evans' contribution to the study protocol, the study coordinator lead and the data collectors at each participating site, Sandy Errey for providing statistical guidance and Ben White for providing technical feedback on this manuscript.

Contributors KMD and KB contributed equally to this paper. KMD was involved in the conception, design, data acquisition, analysis and interpretation, and drafting the manuscript. KB was involved in data analysis and interpretation and drafting of the manuscript. RR and HK were involved in the design, data acquisition and review of the manuscript. MS was involved in data analysis and interpretation and review of the manuscript. CS and JMC were involved in the design, interpretation of data and review of the manuscript. LN was involved in the conception, design, data acquisition, analysis and interpretation, and review of manuscript. All authors read and approved the final manuscript.

Funding This work was supported by the Australian Government Department of Health.

Competing interests None declared.

Patient consent for publication Not required.

Ethics approval The study was approved by Austin Health Human Research Ethics Committee (ref: HREC/17/Austin/83) and site-specific approval was sought when required.

Provenance and peer review Not commissioned; externally peer reviewed.

Data sharing statement The datasets used and/or analysed during the current study are available from the corresponding author on reasonable request.

Open access This is an open access article distributed in accordance with the Creative Commons Attribution Non Commercial (CC BY-NC 4.0) license, which permits others to distribute, remix, adapt, build upon this work non-commercially, and license their derivative works on different terms, provided the original work is properly cited, appropriate credit is given, any changes made indicated, and the use is non-commercial. See: http://creativecommons.org/licenses/by-nc/4.0/.

\section{REFERENCES}

1. Sudore RL, Lum HD, You JJ, et al. Defining advance care planning for adults: a consensus definition from a multidisciplinary delphi panel. J Pain Symptom Manage 2017;53:821-32.

2. Sudore RL, Heyland DK, Lum HD, et al. Outcomes that define successful advance care planning: a delphi panel consensus. J Pain Symptom Manage 2018;55:245-55.

3. Victorian Government. Advance care planning: have the conversation. A strategy for Victorian health services 2014-2018. Victoria, Australia: Department of Health, 2014.

4. Brinkman-Stoppelenburg A, Rietjens JA, van der Heide A. The effects of advance care planning on end-of-life care: a systematic review. Palliat Med 2014;28:1000-25.

5. Houben CHM, Spruit MA, Groenen MTJ, et al. Efficacy of advance care planning: a systematic review and meta-analysis. J Am Med Dir Assoc 2014;15:477-89.

6. Carter RZ, Detering KM, Silvester W, et al. Advance care planning in Australia: what does the law say? Aust Health Rev 2016;40:405-14.

7. Weafer JA. A perspective on advance planning for end-of-life. Dublin, Ireland: Irish Hospice Foundation, 2016.

8. Goffin T. Advance directives as an instrument in an ageing Europe. Eur J Health Law 2012;19:121-40.

9. Hertogh $\mathrm{CM}$. The misleading simplicity of advance directives. Int Psychogeriatr 2011;23:511-5.

10. Russell S. Advance care planning: whose agenda is it anyway? Palliat Med 2014;28:997-9.

11. Tsoh J, Peisah C, Narumoto J, et al. Comparisons of guardianship laws and surrogate decision-making practices in China, Japan, Thailand and Australia: a review by the Asia Consortium, International Psychogeriatric Association (IPA) capacity taskforce. Int Psychogeriatr 2015;27:1029-37.

12. Australian Commission of Quality and Safety in Health Care. The National consensus statement: essential elements for safe and highquality end-of-life care. Sydney, Australia: ACSQHC, 2015. 
13. Advance Care Planning Australia. Advance care planning and the law. https://www.advancecareplanning.org.au/for-health-and-careworkers/legal-requirements (Accessed 24 Apr 2018).

14. Australian Health Ministers' Advisory Council. National framework for advance care directives. Canberra, Australia: Commonwealth Government of Australia, 2011.

15. Ruseckaite R, Detering KM, Evans SM, et al. Protocol for a national prevalence study of advance care planning documentation and selfreported uptake in Australia. BMJ Open 2017;7:e018024.

16. POLST. National POLST Paradigm. http://polst.org/ (Accessed 29 Oct 2018).

17. Australian Medical Association. Position statement on end of life care and advance care planning 2014. Canberra: Australian Medical Association, 2014.

18. General Medical Council. Treatment and care towards the end of life: good practice in decision making. United Kingdom: General Medical Council, 2010.

19. American Medical Association. AMA Code of medical ethics. United States: American Medical Association, 2016.

20. Medical Board of Australia. Good medical practice: a code of conduct for doctors in Australia. Canberra: Medical Board of Australia, 2014.

21. Australian Health Ministers. National palliative care strategy. Canberra, Australia: Commonwealth of Australia, 2010.

22. NSW Ministry of Health. Advance planning for quality care at end of life: action plan 2013-2018. http://www.health.nsw.gov.au/patients/ acp/Pages/acp-plan-2013-2018.aspx (Accessed 19 Apr 2018).

23. Productivity Commission. Introducing competition and informed user choice into human services: reforms to human services, draft report. Canberra, Australia: Productivity Commission, 2017.

24. Urbis. Evaluation of the National palliative care strategy 2010 final report. http://www.health.gov.au/internet/main/publishing nsf/content/EF57056BDB047E2FCA257BF000206168/\$File/ Evaluation\%20of\%20the\%20National\%20Palliative\%20Care\% 20Strategy\%202010\%20Final\%20Report.pdf (Accessed 24 Mar 2018).

25. Bradley SL, Woodman RJ, Tieman JJ, et al. Use of advance directives by South Australians: results from the Health Omnibus Survey Spring 2012. Med J Aust 2014;201:467-9.

26. In der Schmitten J, Lex K, Mellert C, et al. Implementing an advance care planning program in German nursing homes: results of an interregionally controlled intervention trial. Dtsch Arztebl Int 2014;111:50.

27. Sommer S, Marckmann G, Pentzek M, et al. Advance directives in nursing homes: prevalence, validity, significance, and nursing staff adherence. Dtsch Arztebl Int 2012;109:577.

28. Lo YT, Wang JJ, Liu LF, et al. Prevalence and related factors of donot-resuscitate directives among nursing home residents in Taiwan. $J$ Am Med Dir Assoc 2010;11:436-42.

29. McAuley WJ, Buchanan RJ, Travis SS, et al. Recent trends in advance directives at nursing home admission and one year after admission. Gerontologist 2006;46:377-81.

30. Meeussen K, Van den Block L, Echteld M, et al. Advance care planning in Belgium and The Netherlands: a nationwide retrospective study via sentinel networks of general practitioners. J Pain Symptom Manage 2011;42:565-77.

31. O'Sullivan R, Mailo K, Angeles R, et al. Advance directives: survey of primary care patients. Can Fam Physician 2015;61:353-6.

32. Butler J, Binney Z, Kalogeropoulos A, et al. Advance directives among hospitalized patients with heart failure. JACC Heart Fail 2015;3:112-21.
33. Kirkpatrick JN, Guger CJ, Arnsdorf MF, et al. Advance directives in the cardiac care unit. Am Heart J 2007;154:477-81.

34. Yadav KN, Gabler NB, Cooney E, et al. Approximately one in three US adults completes any type of advance directive for end-of-life care. Health Aff 2017;36:1244-51.

35. Dobbs D, Park NS, Jang Y, et al. Awareness and completion of advance directives in older Korean-American adults. J Am Geriatr Soc 2015;63:565-70.

36. Gamertsfelder EM, Seaman JB, Tate J, et al. Prevalence of advance directives among older adults admitted to intensive care units and requiring mechanical ventilation. J Gerontol Nurs 2016;42:34-41.

37. Nair B, Kerridge I, Dobson A, et al. Advance care planning in residential care. Aust N Z J Med 2000;30:339-43.

38. Rao JK, Anderson LA, Lin FC, et al. Completion of advance directives among U.S. consumers. Am J Prev Med 2014;46:65-70.

39. Street M, Ottmann G, Johnstone MJ, et al. Advance care planning for older people in Australia presenting to the emergency department from the community or residential aged care facilities. Health Soc Care Community 2015;23:513-22.

40. White B, Tilse $\mathrm{C}$, Wilson $\mathrm{J}$, et al. Prevalence and predictors of advance directives in Australia. Intern Med J 2014:44:975-80.

41. von Elm E, Altman DG, Egger M, et al. The Strengthening the Reporting of Observational Studies in Epidemiology (STROBE) statement: guidelines for reporting observational studies. PLoS Med 2007;4:e296.

42. Oken MM, Creech RH, Tormey DC, et al. Toxicity and response criteria of the Eastern Cooperative Oncology Group. Am J Clin Oncol 1982;5:649-56.

43. Australian Bureau of Statistics. Regional population by age and sex, Australia. 2017 http://www.abs.gov.au/AUSSTATS/abs@.nsf/ DetailsPage/3235.02017? OpenDocument (Accessed 6 Nov 2017).

44. White B, Willmott L, Cartwright C, et al. Doctors' knowledge of the law on withholding and withdrawing life-sustaining medical treatment. Med J Aust 2014;201:229-32.

45. Bailoor K, Kamil LH, Goldman E, et al. The voice is as mighty as the pen: integrating conversations into advance care planning. J Bioeth Inq 2018;15:185-91.

46. Martin RS, Hayes B, Gregorevic K, et al. The effects of advance care planning interventions on nursing home residents: a systematic review. J Am Med Dir Assoc 2016;17:284-93.

47. Clark D, Armstrong M, Allan A, et al. Imminence of death among hospital inpatients: prevalent cohort study. Palliat Med 2014;28:474-9

48. Scott IA, Mitchell GK, Reymond EJ, et al. Difficult but necessary conversations--the case for advance care planning. Med J Aust 2013;199:662-6.

49. Nedjat-Haiem FR, Carrion IV, Gonzalez K, et al. Exploring health care providers' views about initiating end-of-life care communication. Am $J$ Hosp Palliat Med 2017;34:308-17.

50. O'Hare AM, Szarka J, McFarland LV, et al. Provider Perspectives on Advance Care Planning for Patients with Kidney Disease: Whose Job Is It Anyway? Clin J Am Soc Nephrol 2016;11:855-66.

51. De Vleminck A, Pardon K, Beernaert K, et al. How do general practitioners conceptualise advance care planning in their practice? A Qualitative Study. PLoS One 2016;11:e0153747.

52. Rhee JJ, Zwar NA, Kemp LA. Uptake and implementation of advance care planning in Australia: findings of key informant interviews. Aust Health Rev 2012;36:98-104.

53. Arthritis Research UK. Care planning and musculoskeletal health. Chesterfield, UK: Arthritis Research UK, 2014. 